\title{
Does selenium supplementation affect thyroid function? Results from a randomized, controlled, double-blinded trial in a Danish population
}

\author{
Kristian Hillert Winther, Steen Joop Bonnema, Frederik Cold', Birgit Debrabant ${ }^{2}$, \\ Mads Nybo ${ }^{3}$, Søren Cold ${ }^{1}$ and Laszlo Hegedüs \\ Department of Endocrinology and Metabolism, Odense University Hospital, Kloevervaenget 10, 6. Sal, DK-5000 \\ Odense C, Denmark, 'Department of Oncology, Odense University Hospital, Odense, Denmark, ${ }^{2}$ Department of \\ Epidemiology, Biostatistics and Biodemography, University of Southern Denmark, Odense, Denmark and \\ ${ }^{3}$ Department of Clinical Biochemistry and Pharmacology, Odense University Hospital, Odense, Denmark
}

\author{
Correspondence \\ should be addressed \\ to $\mathrm{K} \mathrm{H}$ Winther \\ Email \\ kristian.winther@rsyd.dk
}

\begin{abstract}
Objective: Selenium is present in the active site of proteins important for thyroid hormone synthesis and metabolism. The objective of this study is to investigate the effect of selenium supplementation in different doses on thyroid function, under conditions of suboptimal dietary selenium intake.

Design: The Danish PREvention of Cancer by Intervention with SElenium pilot study (DK-PRECISE) is a randomized, doubleblinded, placebo-controlled trial. A total of 491 males and females aged $60-74$ years were randomized to $100 \mu \mathrm{g}(n=124)$, $200 \mu \mathrm{g}(n=122)$, or $300 \mu \mathrm{g}(n=119)$ selenium-enriched yeast or matching yeast-based placebo tablets $(n=126)$. A total of 361 participants, equally distributed across treatment groups, completed the 5-year intervention period.

Methods: Plasma samples were analyzed for selenium and serum samples for $\mathrm{TSH}$, free triiodothyronine $\left(\mathrm{FT}_{3}\right)$, and free thyroxine $\left(\mathrm{FT}_{4}\right)$ at baseline, and after 6 months, and 5 years of supplementation.

Results: Plasma selenium concentrations increased significantly and dose-dependently in treatment groups receiving selenium $(P<0.001)$. Serum TSH and $\mathrm{FT}_{4}$ concentrations decreased significantly and dose-dependently by $0.066 \mathrm{mIU} / \mathrm{l}$ $(P=0.010)$ and $0.11 \mathrm{pmol} / \mathrm{l}(P=0.015)$, respectively, per $100 \mu \mathrm{g} /$ day increase, with insignificant differences between 6 months and 5 years. No significant effects were found for $\mathrm{FT}_{3}$ and $\mathrm{FT}_{3}: \mathrm{FT}_{4}$ ratio.

Conclusions: In euthyroid subjects, selenium supplementation minutely and dose-dependently affects thyroid function, when compared with placebo, by decreasing serum TSH and $\mathrm{FT}_{4}$ concentrations. Based on these findings, selenium supplementation is not warranted under conditions of marginal selenium deficiency. However, a role for selenium supplementation in the treatment of autoimmune thyroid diseases is still unresolved.
\end{abstract}

\section{Introduction}

Type 1 and 2 iodothyronine deiodinases (DIO1, DIO2) catalyze the conversion of thyroxine $\left(\mathrm{T}_{4}\right)$ to triiodothyronine $\left(\mathrm{T}_{3}\right)$, which is the primary mediator of the developmental and metabolic effects of the vertebrate thyroid $(1,2,3)$. In addition, the inactivating DIO3 is involved in degradation of the prohormone $\mathrm{T}_{4}$ and the active hormone $\mathrm{T}_{3}$. Around 25 years ago, the cloning of DIO1 implicated selenium as the nucleophilic atom in its active site (4). Selenium is a trace element essential to human health, inserted as selenocysteine residues in the vast majority of 50-70 selenoprotein variants encoded by 25 human genes (5). Several selenoproteins are expressed in thyrocytes, where the most important ones are DIO1, $\mathrm{DIO} 2$, and type 3 glutathione peroxidase (GPx3) protecting thyrocytes from excess $\mathrm{H}_{2} \mathrm{O}_{2}$ generated during thyroid hormone synthesis (6).

In studies contemporary to the efforts toward purifying DIO1, both animal models and human trials suggested

Published by Bioscientifica Ltd. 
impaired DIO1 activity with low selenium intake $(7,8)$. In healthy African schoolchildren with combined severe iodine and selenium deficiency, selenium supplementation vs placebo led to decreases in serum thyrotropin (TSH) and reverse $\mathrm{T}_{3}\left(\mathrm{RT}_{3}\right)$ concentrations, and the authors concluded that selenium intake plays a definite role in thyroid hormone metabolism in humans (8). Dietary selenium intake varies considerably between populations (9). In Denmark, selenium status is considered to be borderline low to adequate, with serum selenium concentration of $98.7 \pm 19.8 \mu \mathrm{g} / \mathrm{l}$ in a recently investigated adult population (10). Interestingly, serum selenium concentration was inversely associated with thyroid volume and goiter in the same population (11). Similar observations in a study among French women (12) support that the thyroid gland also responds to selenium intake at marginal deficiency, where the activity of at least a subset of selenoproteins is not maximized (13). Subsequent intervention studies of the effects of selenium supplementation on thyroid function have yielded equivocal results. In a randomized controlled trial, enrolling 36 elderly Italians, supplementation with $100 \mu \mathrm{g} /$ day sodium selenite for 3 months decreased $\mathrm{T}_{4}$ concentrations (14) when compared with placebo, and in a US intervention study among 28 healthy adults, a small but significant increase in $\mathrm{T}_{3}$ concentrations was seen in men during supplementation with $200 \mu \mathrm{g} /$ day selenomethionine for 28 months (15). In contrast, no effects on thyroid hormone concentrations or conversion were found in two larger randomized controlled trials in euthyroid populations and using another selenium compound $(16,17)$. In the UK, 368 elderly individuals received 100, 200, or $300 \mu \mathrm{g} /$ day selenium-enriched yeast or placebo-yeast for 6 months (16), and in New Zealand, 172 healthy adults received $200 \mu \mathrm{g} /$ day selenium-enriched yeast or placebo-yeast for 21 weeks (17). Prioritized expression of DIOs under different degrees of selenium-deficiency may account for the lack of clear-cut effects in healthy individuals (18).

This randomized long-term follow-up study offers an opportunity to add to the ambiguous and limited human trial data on the physiological importance of selenium intake, in a range of doses, for thyroid function in a population with marginally low selenium status.

\section{Subjects and methods}

\section{Study design}

The PREvention of Cancer by Intervention with SElenium (DK PRECISE) pilot trial (ClinicalTrials.gov ID:
NCT01819649) was a single-center, nonstratified, randomized, double-blinded, placebo-controlled, multiarm parallel clinical trial with four groups (allocation ratio 1:1:1:1). The sample size was set at 500 participants to draw reasonable conclusions about recruitment, adherence, and loss to follow-up, while keeping the costs within reasonable bounds, in the preparations of a large-scale international PRECISE trial. Due to these circumstances, no formal power calculations were performed.

\section{Participants}

Participants were males and females aged 60-74 years from the County of Funen, Denmark. Invitation letters were sent out based on a random sample from the Danish Civil Registration System. From November 1998 to June 1999, 2897 potential participants were invited. Among them, 630 accepted the invitation for a visit to Odense University Hospital where they were screened for inclusion. Exclusion criteria were: i) a Southwest Oncology Group performance status score $>1$; ii) active liver or kidney disease (alanine-aminotransferase, alkaline phosphatase, bilirubin, or urea two s.D. above the upper reference range limit); iii) previous diagnosis of cancer (excluding nonmelanoma skin cancer); iv) diagnosed HIV infection; v) receiving immunosuppressive therapy; vi) unable to understand written or spoken information; and vii) receiving $\geq 50 \mu \mathrm{g} /$ day of selenium supplements in the previous 6 months (self reported).

The participants deemed suitable for inclusion provided blood samples and were given yeast tablets for an open-label 4-week placebo run-in phase. After this, potential participants returned for a second visit for a final evaluation of inclusion and exclusion criteria, participant adherence, and satisfaction during the runin phase. Good adherence was defined as taking more than $80 \%$ of the run-in phase tablets assessed by tablet count.

The 491 subjects who met the inclusion criteria displayed good adherence in the run-in phase, gave written informed consent, and were enrolled and randomized to $0,100,200$, or $300 \mu \mathrm{g}$ of selenium daily (Fig. 1). The regional Data Protection Agency and Scientific Ethical Committees of Vejle and Funen counties approved the study (journal no. 19980186).

\section{Randomization and interventions}

Randomization was computer-generated, blocked, and nonstratified, and was performed at the Division of 


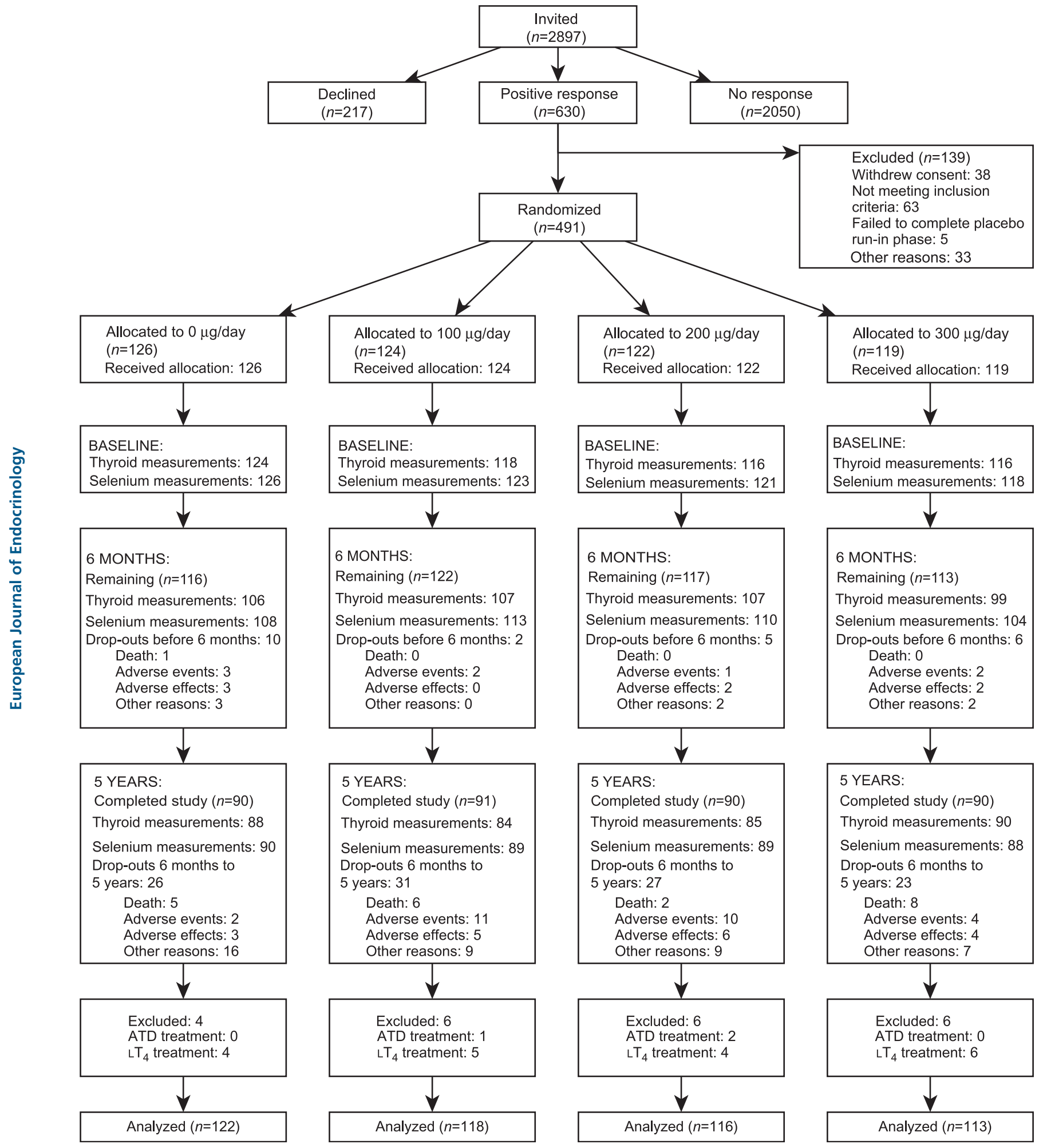

Figure 1

Study flow diagram. 
Epidemiology and Biostatistics, University of Arizona, Arizona Cancer Center. A badge number system secured blinding and correct distribution of selenium doses. The responsibility of distributing tablets was placed with pharmacists at Odense University Hospital.

The intervention agent was the selenium-enriched yeast SelenoPrecise and tablets were formulated and packaged by Pharma Nord ApS, Vejle, Denmark. The placebo agent was an inactive spray-dried baker's yeast, comprising $250 \mathrm{mg}$ yeast placebo, $80 \mathrm{mg}$ cellulose, $65 \mathrm{mg}$ dicalcium phosphate, and $\leq 5 \mathrm{mg}$ other inactive ingredients, identical in appearance to the selenium tablets. Both intervention and placebo tablets were coated with titanium oxide in order to obtain identical smell and taste. Tablets were packaged in blister packs of 28 tablets, $7 \times 4$. The participants, research staff, and investigators were blinded to treatment.

\section{Sample and data collection}

The participants were evaluated at Odense University Hospital. Blood was drawn at baseline, 6, 12, 18, 24, and 60 months. Participants were at nonfasting. Heparinized plasma and serum were prepared and stored at $-80^{\circ} \mathrm{C}$. Reasons for participant withdrawal were recorded.

\section{Biochemical analyses}

Total selenium concentrations at baseline and at the 6-month and 5-year visits were measured in lithiumheparin plasma at LGC Limited, Teddington, UK, between July 2012 and March 2013, using inductively coupledplasma mass spectrometry with external calibration. A matrix certified reference material, BCR-637 Human Serum, with a certified selenium concentration of $81 \pm$ $7 \mu \mathrm{g} / \mathrm{l}$ selenium (density corrected $79.1 \mathrm{ng} / \mathrm{g}$ ), was used for quality control of the total selenium measurements. The selenium concentration found for BCR-637 was 78.3 \pm $2.7 \mu \mathrm{g} / 1$ Se (16 independent replicates) indicating good accuracy of the method. The intra-assay coefficients of variation ( $\mathrm{CV}$ values) ranged from $0.5 \%$ for samples of high to $3 \%$ for samples of low selenium concentration. The inter-assay CV was 3.4\%.

Serum TSH, free $\mathrm{T}_{3}\left(\mathrm{FT}_{3}\right)$, free $\mathrm{T}_{4}\left(\mathrm{FT}_{4}\right)$, and thyroid peroxidase antibodies (TPO-Ab) concentrations at baseline and at the 6-month and 5-year visits were measured at the Department of Clinical Biochemistry, Odense University Hospital, Denmark, between September 2013 and March 2014. All measurements were serial to avoid interassay variation. TSH concentrations were measured with a chemiluminescence microparticle immunoassay. The analysis was performed on an Architect i2000 (Abbott, Wiesbaden, Germany) with a documented limit of detection (LOD) $\leq 0.01 \mathrm{mIU} / 1$. The intra-assay variation coefficient was $<2 \%$ and the reference range was $0.3-4.0 \mathrm{mIU} / 1 . \mathrm{FT}_{3}, \mathrm{FT}_{4}$, and $\mathrm{TPO}-\mathrm{Ab}$ concentrations were analyzed using time-resolved fluoroimmunoassays. The analyses were performed on AutoDELFIA equipment (Wallac, Turku, Finland) and LOD was $1.5 \mathrm{pmol} / \mathrm{l}\left(\mathrm{FT}_{3}\right)$, $2 \mathrm{pmol} / \mathrm{l}\left(\mathrm{FT}_{4}\right)$, and $1 \mathrm{mIU} / \mathrm{l}$ (TPO-Ab). The intra-assay variation coefficients were $<5 \%\left(\mathrm{FT}_{3}\right),<2 \%\left(\mathrm{FT}_{4}\right)$, and $3.4 \%$ (TPO-Ab), and the reference ranges were $4.3-7.4$ $\left(\mathrm{FT}_{3}\right)$, 9.9-17.7 pmol/1 $\left(\mathrm{FT}_{4}\right)$, and $<15 \mathrm{mIU} / \mathrm{l}$ (TPO-Ab) $(19,20)$.

\section{Statistical analysis}

The effect of different doses of selenium supplementation was investigated by regression analysis for five different outcomes: selenium, TSH, $\mathrm{FT}_{3}, \mathrm{FT}_{4}$ and $\mathrm{FT}_{3}: \mathrm{FT}_{4}$ ratio.

For this, we applied a population averaged procedure assuming a linear relationship between outcome and covariates, by use of population-averaged generalized estimating equations (PA-GEE) combined with a sandwich estimator (21). This approach accommodates repeated measurements without requiring a constant within-subject variation, and encompasses continuous non-normal outcomes. Each outcome was analyzed in two analyses, with one analysing active treatment vs placebo as a binary covariate, and another analysing intervention dose as a continuous covariate (with values 0, 100, 200, or $300 \mu \mathrm{g} /$ day selenium-enriched yeast). Other included covariates were the baseline values of the respective outcome, age at baseline, gender, and a binary variable indicating the actual duration of the treatment ( 5 years vs 6 months). In addition, we included an interaction analysis between the treatment variable (either continuous or binary) and the treatment duration. To obtain our final analyses, we used a stepwise regression selection approach. The analyses underwent reduction and extension iterating between, firstly, removing explanatory variables one at a time, which no longer contributed significantly to the model ( $P$ value $>0.05)$, and secondly, screening explanatory variables not contained in the current model one at a time and adding the most significant one ( $P$ value $\leq 0.05)$. Observations were analyzed irrespective of compliance (intention-to-treat analysis). For significant interactions, main effects were forced into the model. All reported $P$ values were two-sided. Statistical analyses were 
performed with Stata, version 13 (StataCorp, College Station, TX, USA).

\section{Results}

\section{Participants}

Of the 491 randomized participants, 23 dropped out of treatment before 6 months of follow-up, 107 participants dropped out between 6 months and 5 years, and the remaining 361 (74\%) participants completed the 5-year follow-up period (Fig. 1). The 130 participants who withdrew before the end of the study period were equally distributed across treatment groups $(P=0.91)$. Twenty-two participants receiving thyroid medication at baseline or after 5 years, supplementation, with no significant differences between treatment groups at any time $(P=0.20$ and 0.40 respectively), were excluded from the statistical analysis. Thyroid function measurements were available for 467 of the remaining 469 participants at baseline, for 410 at 6 months, and for 338 at 5 years (Fig. 1). Participants with and without available thyroid function measurements at 6 months and 5 years did not differ in their baseline characteristics (data not shown). Three participants allocated to placebo had plasma selenium concentrations more than two inter-quartile ranges (IQRs) above the median at 5 years $(3.3 \%)$, so drop-ins were deemed rare.

\section{Adverse events}

Twenty-two participants died during the 5-year follow-up period and 35 participants discontinued the study due to nonfatal adverse events (Fig. 1), with no significant differences across treatment groups $(P=0.29$ and 0.14 respectively). Twenty-five participants withdrew due to adverse reactions to treatment (Fig. 1), which were mainly hair loss, skin reactions, and grooved nails. These reactions were equally associated with selenium and placebo and were independent of selenium dose $(P=0.84)$. Plasma selenium concentrations for participants dropping out due to alleged adverse reactions were within IQRs for respective treatment groups before drop out, except for two participants in the $300 \mu \mathrm{g} /$ day group who had plasma selenium concentrations below the group IQR before dropout (data not shown). This indicates that adverse reactions reported were unlikely to result from excessive use of trial medication or other selenium supplements.

\section{Baseline characteristics}

There were no significant differences between treatment groups at baseline in TPO-Ab positivity, or other participant characteristics (Table 1). The overall median (IQR) plasma selenium concentration at baseline was 85 (19) $\mathrm{ng} / \mathrm{g}$ with no significant differences across treatment

Table 1 Baseline characteristics of trial participants overall and by treatment group. Data are presented as means (s.D.) or numbers (\%).

\begin{tabular}{|c|c|c|c|c|c|c|}
\hline \multirow[b]{2}{*}{ Characteristic } & \multirow[b]{2}{*}{ Overall } & \multirow[b]{2}{*}{ Placebo } & \multicolumn{3}{|c|}{ Selenium dose ( $\mu \mathrm{g} /$ day) } & \multirow[b]{2}{*}{ P value $^{a}$} \\
\hline & & & 100 & 200 & 300 & \\
\hline Participants & 491 & 126 & 124 & 122 & 119 & \\
\hline Age (years) & $66.1(4.1)$ & $65.4(3.8)$ & $66.4(4.2)$ & $66.3(4.4)$ & $66.5(4.1)$ & 0.13 \\
\hline Sex & & & & & & 0.49 \\
\hline Men & $255(51.9)$ & $60(47.6)$ & $70(56.5)$ & $66(54.1)$ & $59(49.6)$ & \\
\hline Women & $236(48.1)$ & $66(52.4)$ & $54(43.5)$ & 56 (45.9) & $60(50.4)$ & \\
\hline Smoking status & & & & & & 0.49 \\
\hline Never & $160(32.6)$ & $35(27.8)$ & $42(33.9)$ & $40(32.8)$ & $43(36.2)$ & \\
\hline Former & $185(37.7)$ & $48(38.1)$ & 47 (37.9) & $52(42.6)$ & 38 (31.9) & \\
\hline Current & $146(29.7)$ & $43(34.1)$ & $35(28.2)$ & $30(24.6)$ & 38 (31.9) & \\
\hline Alcohol status (drinks/week) & & & & & & 0.76 \\
\hline$\leq 2$ & $170(34.6)$ & $47(37.3)$ & $41(33.1)$ & $40(32.8)$ & $42(35.3)$ & \\
\hline $3-10$ & $209(42.6)$ & $48(38.1)$ & $51(41.1)$ & $55(45.1)$ & $55(46.2)$ & \\
\hline$>10$ & $112(22.8)$ & $31(24.6)$ & $32(25.8)$ & $27(22.1)$ & $22(18.5)$ & \\
\hline BMI $\left(k g / m^{2}\right)$ & $26.8(4.1)$ & $26.5(4.0)$ & $27.1(4.0)$ & $27.2(4.3)$ & $26.5(4.0)$ & 0.40 \\
\hline Use of thyroid medication ${ }^{b}$ & $14(2.9)$ & $2(1.6)$ & $4(3.2)$ & $5(4.1)$ & $3(2.5)$ & 0.20 \\
\hline TPO-Ab (units/ml) & & & & & & 0.33 \\
\hline$<15$ & $409(87.6)$ & $111(91)$ & $98(83.1)$ & $101(86.3)$ & $99(87.6)$ & \\
\hline$\geq 15$ & $61(12.4)$ & $11(9)$ & 20 (16.9) & $16(13.7)$ & $14(12.4)$ & \\
\hline
\end{tabular}

TPO-Ab, thyroid peroxidase antibodies.

${ }^{a} P$ value for homogeneity of means (one-way ANOVA tests) or proportions ( $\chi^{2}$ tests) across the four treatment groups.

${ }^{b}$ Thyroid hormone substitution or antithyroid medication. 
Table 2 Plasma selenium concentrations and thyroid function at baseline and after 6 months and 5 years of selenium supplementation. $P$ values are from Kruskal-Wallis tests comparing the four intervention groups at baseline.

\begin{tabular}{|c|c|c|c|c|c|c|}
\hline \multirow[b]{2}{*}{ Variable } & \multirow[b]{2}{*}{ Overall } & \multirow{2}{*}{$\begin{array}{c}\text { Placebo } \\
100\end{array}$} & \multicolumn{3}{|c|}{ Selenium dose ( $\mu \mathrm{g} / \mathrm{day})$} & \multirow[b]{2}{*}{$P$ value } \\
\hline & & & 200 & 300 & & \\
\hline \multicolumn{7}{|l|}{ Plasma selenium (ng/g) } \\
\hline Median at baseline (IQR) & $85(19)$ & $85(20)$ & $86(18)$ & $88(22)$ & 84 (19) & 0.22 \\
\hline Median at 6 months (IQR) & & $87(22)$ & $149(28)$ & $201(58)$ & $246(70)$ & \\
\hline Median at 5 years (IQR) & & $85(16)$ & $157(33)$ & $217(46)$ & $271(106)$ & \\
\hline \multicolumn{7}{|l|}{ Serum TSH (mIU/l) } \\
\hline Median at baseline (IQR) & $1.20(0.90)$ & $1.21(0.81)$ & $1.28(0.94)$ & $1.14(0.95)$ & $1.18(0.89)$ & 0.68 \\
\hline Median at 6 months (IQR) & & $1.19(0.76)$ & $1.20(1.01)$ & $1.26(0.84)$ & $1.09(0.82)$ & \\
\hline Median at 5 years (IQR) & & $1.22(1.02)$ & $1.17(0.79)$ & $1.32(0.84)$ & $1.06(0.85)$ & \\
\hline \multicolumn{7}{|l|}{ Serum $\mathrm{FT}_{3}(\mathrm{pmol} / \mathrm{l})$} \\
\hline Median at baseline (IQR) & $5.53(0.76)$ & $5.44(0.77)$ & $5.56(0.71)$ & $5.54(0.68)$ & $5.56(0.83)$ & 0.39 \\
\hline Median at 6 months (IQR) & & $5.52(0.88)$ & $5.59(0.81)$ & $5.55(0.77)$ & $5.55(0.81)$ & \\
\hline Median at 5 years (IQR) & & $5.54(0.95)$ & $5.59(0.71)$ & $5.58(0.78)$ & $5.53(0.78)$ & \\
\hline \multicolumn{7}{|l|}{ Serum $\mathrm{FT}_{4}(\mathrm{pmol} / \mathrm{l})$} \\
\hline Median at baseline (IQR) & $13.21(2.49)$ & $12.88(2.67)$ & $13.06(2.8)$ & $13.43(2.28)$ & $13.43(2.38)$ & 0.13 \\
\hline Median at 6 months (IQR) & & $12.91(2.97)$ & $13.00(2.6)$ & $13.43(2.3)$ & $12.82(2.2)$ & \\
\hline Median at 5 years (IQR) & & $13.32(3.07)$ & $13.52(2.88)$ & $13.24(2.08)$ & $13.25(2.12)$ & \\
\hline \multicolumn{7}{|l|}{ Serum $\mathrm{FT}_{3}: \mathrm{FT}_{4}$ ratio } \\
\hline Median at baseline (IQR) & $0.42(0.08)$ & $0.43(0.07)$ & $0.43(0.10)$ & $0.42(0.07)$ & $0.42(0.07)$ & 0.19 \\
\hline Median at 6 months (IQR) & & $0.42(0.08)$ & $0.43(0.09)$ & $0.41(0.06)$ & $0.42(0.09)$ & \\
\hline Median at 5 years (IQR) & & $0.42(0.09)$ & $0.42(0.09)$ & $0.42(0.07)$ & $0.42(0.08)$ & \\
\hline
\end{tabular}

$\mathrm{IQR}$, interquartile range; $\mathrm{TSH}$, thyrotropin; $\mathrm{FT}_{3}$, free triiodothyronine; $\mathrm{FT}_{4}$, free thyroxine.

groups (Table 2). The overall medians (IQRs) for thyroid function parameters at baseline were TSH $1.20(0.90)$ $\mathrm{mIU} / \mathrm{l}, \mathrm{FT}_{3} 5.53$ (0.76) pmol/1, $\mathrm{FT}_{4} 13.21$ (2.49) $\mathrm{pmol} / \mathrm{l}$, and calculated $\mathrm{FT}_{3}: \mathrm{FT}_{4}$ ratio $0.42(0.08)$ with no significant differences across treatment groups (Table 2).

\section{Intention-to-treat analysis}

The results of the PA-GEE regression analyses are summarized below and in Table 3 and Fig. 2 .

Plasma selenium - As expected, selenium supplementation significantly increased plasma selenium concentrations compared with placebo in the binary covariate model $(P<0.001)$ as well as in the dose model $(P<0.001)$ (Table 3$)$. In both models, treatment duration enhanced the effect ( $P=0.008$ and 0.025 respectively). Regression slopes based on the dose model estimate the magnitude of this effect, with a dose increase of $100 \mu \mathrm{g} /$ day selenium-enriched yeast increasing plasma selenium concentrations by, on average, $57 \mathrm{ng} / \mathrm{g}$ at 6 months and $64 \mathrm{ng} / \mathrm{g}$ at 5 years' intervention (Table 3 and Fig. 2A). Female gender increased plasma selenium concentrations significantly in both models $(P<0.001$, Table 3$)$.
Serum TSH $\bullet$ Baseline TSH concentration affected outcome TSH concentrations with an increase of $1.0 \mathrm{mIU} / \mathrm{l}$ at baseline, increasing TSH by $0.65 \mathrm{mIU} / 1$ at later time points $(P<0.001$, Table 3$)$. In the binary model of active treatment vs placebo, we could not detect any impact of selenium supplementation on TSH $(P=0.61$, Table 3$)$, but in the dose model, increasing the selenium dose affected TSH ( $P=0.010$, Table 3$)$. A time-independent regression slope quantified that each dose increase of $100 \mu \mathrm{g} /$ day decreased serum TSH concentration by, on average, $0.066 \mathrm{mIU} / 1$ (Table 3 and Fig. 2B). Subsequently, in a binary model of $300 \mu \mathrm{g}$ selenium-enriched yeast/day vs other treatment groups, the highest selenium dose significantly decreased serum TSH by, on average, $0.21 \mathrm{mIU} / \mathrm{l}(P=0.003)$. Other covariates were found not to have a significant impact.

Serum $\mathrm{FT}_{3}$ - Baseline $\mathrm{FT}_{3}$ concentrations, as for TSH, affected outcome concentrations. An increase of $1.0 \mathrm{pmol} / \mathrm{l}$ at baseline increased $\mathrm{FT}_{3}$ by, on average, $0.49 \mathrm{pmol} / \mathrm{l}$ at later time points $(P<0.001$, Table 3$) . \mathrm{FT}_{3}$ concentrations decreased at later time points in female participants $(P=0.021$ and 0.031 , Table 3$)$. Neither in the binary model $(P=0.48$, Table 3$)$ nor in the dose model $(P=0.51$, Table 3$)$ did we find an effect of selenium 
Table 3 Population averaged general estimating equations (PA-GEE) regression analyses results. For each outcome variable, covariates included in the final binary and dose analyses respectively are reported with estimated regression coefficients $\beta$, corresponding S.E.M., and nominal $P$ values.

\begin{tabular}{|c|c|c|c|}
\hline \multirow[b]{2}{*}{ Outcome } & \multicolumn{3}{|c|}{ Binary analysis } \\
\hline & Covariates & Estimated $\beta$ (s.E.M.) & Nominal $P$ value \\
\hline \multirow[t]{4}{*}{ Selenium (ng/g) } & Constant & $69.8(3.3)$ & $<0.001$ \\
\hline & Female gender & $29.2(5.3)$ & $<0.001$ \\
\hline & Treatment time & $9.4(4.2)$ & 0.025 \\
\hline & Active treatment & $120.9(3.8)$ & $<0.001$ \\
\hline \multirow[t]{3}{*}{$\mathrm{TSH}(\mathrm{mlU} / \mathrm{l})$} & Constant & $0.53(0.21)$ & 0.013 \\
\hline & Baseline TSH & $0.65(0.15)$ & $<0.001$ \\
\hline & Active treatment & $-0.035(0.071)$ & 0.611 \\
\hline \multirow[t]{4}{*}{$\mathrm{FT}_{3}(\mathrm{pmol} / \mathrm{l})$} & Constant & $3.0(0.22)$ & $<0.001$ \\
\hline & Baseline $T_{3}$ & $0.49(0.037)$ & $<0.001$ \\
\hline & Female gender & $-0.14(0.059)$ & 0.021 \\
\hline & Active treatment & $-0.64(0.91)$ & 0.484 \\
\hline \multirow[t]{5}{*}{$\mathrm{FT}_{4}(\mathrm{pmol} / \mathrm{l})$} & Constant & $6.3(1.3)$ & $<0.001$ \\
\hline & Baseline $\mathrm{FT}_{4}$ & $0.69(0.059)$ & $<0.001$ \\
\hline & Baseline age & $-0.031(0.014)$ & 0.023 \\
\hline & Treatment time & $0.17(0.083)$ & 0.036 \\
\hline & Active treatment & $-0.21(0.12)$ & 0.096 \\
\hline \multirow[t]{3}{*}{$\mathrm{T}_{3}: \mathrm{T}_{4}$} & Constant & $0.14(0.026)$ & $<0.001$ \\
\hline & Baseline $T_{3}: T_{4}$ & $0.68(0.058)$ & $<0.001$ \\
\hline & Active treatment & $-0.068(0.83)$ & 0.934 \\
\hline
\end{tabular}

\begin{tabular}{|c|c|c|}
\hline \multicolumn{3}{|c|}{ Dose analysis } \\
\hline Covariates & Estimated $\beta$ (S.E.M.) & Nominal $P$ value \\
\hline Constant & $79.0(2.5)$ & $<0.001$ \\
\hline Female gender & $23.8(3.6)$ & $<0.001$ \\
\hline Treatment time* & $6.7(2.5)$ & 0.008 \\
\hline Selenium dosage & $57(1.7)$ & $<0.001$ \\
\hline Constant & $-0.60(0.21)$ & 0.004 \\
\hline Baseline TSH & $0.65(0.15)$ & $<0.001$ \\
\hline Selenium dosage & $-0.066(0.026)$ & 0.010 \\
\hline Constant & $2.9(0.22)$ & $<0.001$ \\
\hline Baseline $T_{3}$ & $0.49(0.037)$ & $<0.001$ \\
\hline Female gender & $-0.13(0.061)$ & 0.031 \\
\hline Selenium dosage & $-0.02(0.03)$ & 0.508 \\
\hline Constant & $6.2(1.2)$ & $<0.001$ \\
\hline Baseline $\mathrm{FT}_{4}$ & $0.69(0.058)$ & $<0.001$ \\
\hline Baseline age & $-0.031(0.013)$ & 0.022 \\
\hline Treatment time & $0.18(0.083)$ & 0.035 \\
\hline Selenium dosage & $-0.11(0.047)$ & 0.015 \\
\hline Constant & $0.13(0.026)$ & $<0.001$ \\
\hline Baseline $T_{3}: T_{4}$ & $0.68(0.058)$ & $<0.001$ \\
\hline Selenium dosage & $-0.0011(0.0027)$ & 0.692 \\
\hline
\end{tabular}

$\mathrm{TSH}$, thyrotropin; $\mathrm{FT}_{3}$, free triiodothyronine; $\mathrm{FT}_{4}$, free thyroxine.

supplementation, or any other covariates, on $\mathrm{FT}_{3}$ (Fig. 2C).

Serum $\mathrm{FT}_{4}$ • Baseline $\mathrm{FT}_{4}$ concentrations affected outcome concentrations, with an increase of $1.0 \mathrm{pmol} / \mathrm{l}$ at baseline increasing $\mathrm{FT}_{4}$ by average $0.69 \mathrm{pmol} / \mathrm{l}$ at later time points $(P<0.001$, Table 3$)$. $\mathrm{FT}_{4}$ concentrations at 5 years were found to be on average 0.17 and $0.18 \mathrm{pmol} / 1$ higher than at 6 months $(P=0.036$ and 0.035 respectively, Table 3$)$. In line with the results for TSH, no effect of selenium supplementation on $\mathrm{FT}_{4}$ was observed in the binary model $(P 0.10$, Table 3), while a significant effect was found in the dose model ( $P=0.015$, Table 3$)$. Thus, a dose increase of $100 \mu \mathrm{g}$ selenium/day decreased serum $\mathrm{FT}_{4}$ by average $0.11 \mathrm{pmol} / 1$ (Fig. 2D). Other covariates with significant impacts were age at baseline, which lowered $\mathrm{FT}_{4}$ on average by $0.031 \mathrm{pmol} / 1$ for each 1-year increase in age in both the binary and continuous dose covariate models $(P=0.023$ and 0.022 , Table 3) and the treatment duration.

Serum $\mathrm{FT}_{3}: \mathrm{FT}_{4}$ ratio $\downarrow$ Baseline $\mathrm{FT}_{3}: \mathrm{FT}_{4}$ ratio affected outcome ratios, with an increase of one $>$ at baseline, increasing later time point ratios on average by 0.68 $(P<0.001$, Table 3$)$. No significant effects of other covariates were found, including selenium supplementation ( $P=0.93$ and 0.69 , Table 3$)$.

\section{Discussion}

In this prospective, randomized, double-blinded, controlled trial among elderly Danes, selenium supplementation affected thyroid function by dose dependently decreasing serum $\mathrm{TSH}$ and $\mathrm{FT}_{4}$ concentrations. Our trial also provided additional data on selenium status in Denmark. The median overall baseline plasma selenium concentration of $85 \mathrm{ng} / \mathrm{g}$ can be converted to $87.3 \mu \mathrm{g} / \mathrm{l}$ by multiplying with 1.027 (the density of plasma). The slightly lower selenium status in our study population, compared with mean serum concentrations found in two previous Danish investigations, $98.7 \mu \mathrm{g} / \mathrm{l}$ (10) and $94 \mu \mathrm{g} / 1$ (22), can at least partly be explained by declining selenium status with age above 60 years $(23,24)$. Plasma selenium concentrations, as expected, increased dose dependently, with a large increase from baseline to 6-month measurements, and a further small increase from 6 months to 5 years. This is in accordance with a previous report of dose-dependent increases plateauing at 9-12 months of selenium supplementation (25).

While previous trials have reported conflicting results, our main findings of the effects on thyroid function are in contrast to the most readily comparable study, the UK PRECISE pilot trial: in 368 elderly individuals receiving 6 months of supplementation with 100, 200, or $300 \mu \mathrm{g} /$ day selenium-enriched yeast or placebo-yeast, 
A

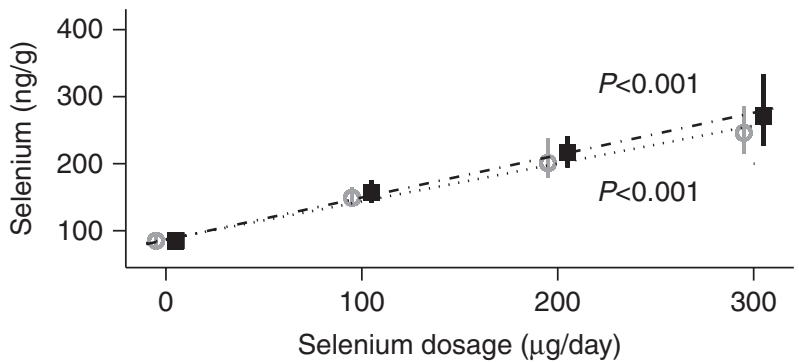

C

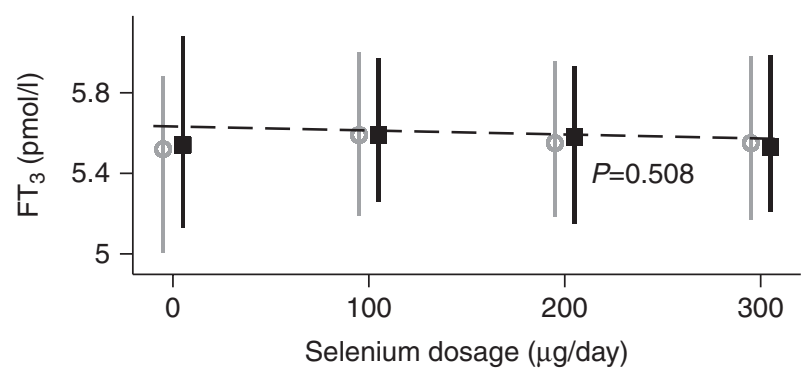

B

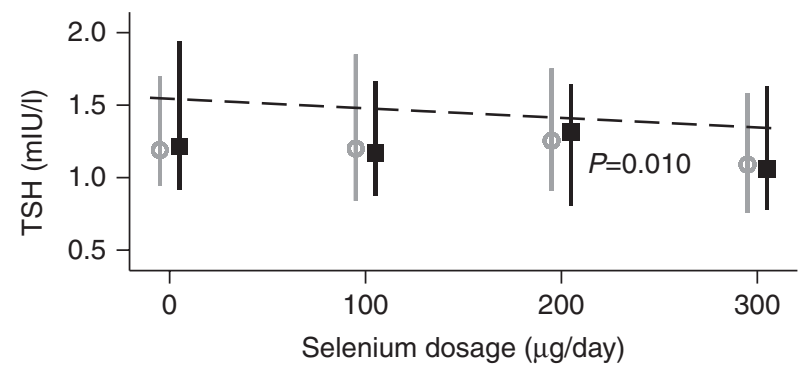

D

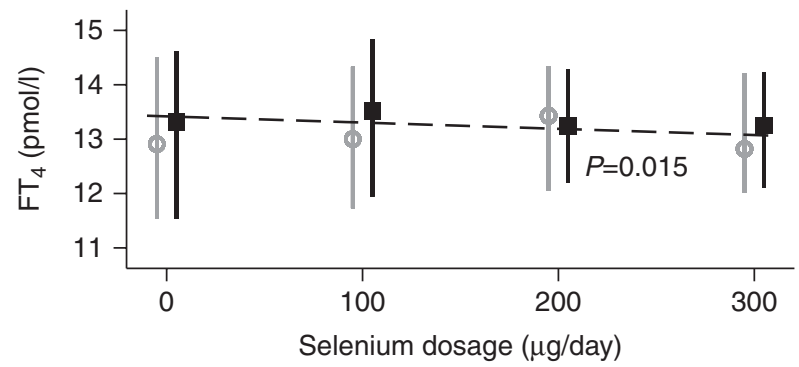

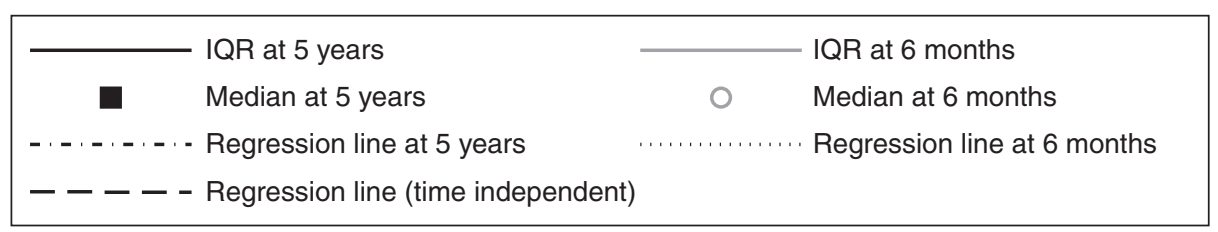

Figure 2

Dose effect diagram illustrating the dose-dependent effects of selenium supplementation on plasma selenium concentrations (A), serum TSH concentrations (B), serum $\mathrm{FT}_{3}$ concentrations (C) and serum $\mathrm{FT}_{4}$ concentrations (D) after 6 months and 5 years.

and using the same study protocol as this study, no effects on thyroid function or thyroid hormone conversion were found (17). In our favor, compared with the UK study, the DK PRECISE trial was slightly larger and continued for 5 years enabling assessment of trend, and both short-term and long-term supplementation, in a more powerful statistical analysis. Effects were significant in our study already after 6 months intervention. Interestingly, our short-term findings are in accordance with a recent study, in which $\sim 6$ months low-dose selenium supplementation decreased $\mathrm{FT}_{4}$ and tended to decrease TSH, when compared with placebo (21). The comparability is however limited as study subjects were pregnant women and effects were seen only in thyroid antibody-positive individuals.

For our statistical analysis, to take the correlation between the repeated measurements into account, we first considered a mixed effects linear model with a subjectspecific random effect. Estimated residuals as well as random effects did however show strong deviations from the model assumptions of independently and identically normally distributed residuals. Moreover, neither transformations of outcome variables, such as logarithmic transformation, nor allowing for nonlinear relationships, by including higher order terms, improved the residual diagnostics. Therefore, we chose a PA-GEE model in order to weaken the distributional assumptions, combined with a sandwich estimator being robust in the case of misspecification of the variance or covariance structure $(26,27,28)$.

It is well known that the thyroid gland retains selenium and selenoprotein activity even under conditions of severe deficiency (29). However, it remains unknown whether selenium modulates peripheral thyroid hormone action via less prioritized mechanisms (18). $\mathrm{T}_{3}: \mathrm{T}_{4}$ ratio is primarily dependent on the DIO1 activity (30), but DIO2 and DIO3 have been implicated in finetuning local intracellular $\mathrm{T}_{3}$ concentrations tissue specifically, without changing serum $\mathrm{T}_{3}$ concentrations (31). Previous trials may have been underpowered, due to 
size or statistical analysis strategy, to detect small changes generated by altered thyroid metabolic states in selenium-sensitive target organs. Optimizing selenoprotein activity is often referred to when explaining the effects of selenium supplementation (32) and indeed, selenium repletion is followed by a rapid accumulation of selenium in endocrine organs and the brain (29). An increased activity of pituitary DIO2 leading to higher production of $\mathrm{T}_{3}$ may explain the net effect of concurrent decreases in serum TSH and $\mathrm{FT}_{4}$ concentrations, e.g. via altered hepatic elimination of thyroid hormone metabolites as suggested in animal experimental studies (33). In this study, however, the three active groups were all supplemented beyond optimal status threshold (13), so the dose-dependent effect of selenium supplementation on thyroid function suggests not merely a correction of deficit. In fact, DIO upregulation may be unrelated to the intracellular accumulation of selenium (34), and supra-physiological, potentially toxic, effects on thyroid hormone metabolism, beyond classical DIO and GPx3 pathways, offer alternative explanations of our findings. Direct effects of iodine and selenium on the pituitary gland, in the principle of a negative feedback loop, have recently been suggested (35). This could account for decreasing TSH concentrations in our study, warranting further investigations of relationships between the thyroid and pituitary glands at the level of trace elements.

The DK PRECISE pilot trial differs from most earlier intervention studies, and from the UK PRECISE trial in particular, in the concomitant mandatory iodization of Danish salt, offering selenium-iodine interaction as explanation of the different effects observed. In Denmark, median urinary iodine concentrations increased from $61 \mu \mathrm{g} / 1$ (1997-1998) to $101 \mu \mathrm{g} / 1$ (2004-2005), following iodine fortification (36). The PRECISE intervention period was 1998-1999 to 2004, and it is very likely that the placebo group increased their intake of iodine alone during the 5-year trial period, while the intervention groups increased their intake of selenium as well. Iodine status has been postulated to be a determinant of selenium activity in patients with thyroid autoimmunity (6), but could not be quantified in the PRECISE trial, since no urine samples were collected. The lack of iodine assessment is the single most important limitation to our study. However, no such synergistic effects were found in a randomized trial with concomitant iodine and selenium supplementation in a New Zealand population of similar selenium and iodine status (37). Furthermore, the iodine fortification program in Denmark was associated with an increase in the TPO-Ab positivity prevalence (38). An attenuating modulation of this effect by selenium is conceivable, due to its potential to decrease thyroid antibodies in autoimmune thyroid disease (39). However, this trial was not designed or powered to investigate the effect of selenium supplementation on TPO-Ab prevalence, and TPO-Ab was measured merely to evaluate potential differences between groups at baseline.

The participants were invited via a random sample from the Danish Civil Registration System. Around 20\% accepted the invitation and this constitutes a potential selection bias, as the age range (60-74 years) is the only known parameter about individuals declining or not responding to the invitation. The narrow age range of participants limits the applicability of our findings to a general population and the relatively low baseline selenium status makes it difficult to extend our findings to populations with higher baseline selenium status, e.g. most of the USA (9). At the time of the biochemical analyses, baseline samples had been stored at $-80{ }^{\circ} \mathrm{C}$ for $\sim 15$ years. A study of stored samples from the Finnish Maternity Cohort concluded that TSH, $\mathrm{FT}_{3}$, and $\mathrm{FT}_{4}$ can be reliably analyzed in serum stored for 23 years and TPO-Ab for 14 years at $-25^{\circ} \mathrm{C}(40)$. It follows that our samples, stored at $-80^{\circ} \mathrm{C}$, should be at least as stable.

Bearing in mind the inextricable U-shaped link between selenium intake and human health (32), our finding of dose-dependent alterations of thyroid function with minute effect sizes does not support universally increasing selenium intake for improving thyroid function under conditions of marginal selenium deficiency. However, the fact that thyroid function appears to be sensitive to selenium supplementation adds to the incentive for investigating its effects on multifactorially regulated traits, such as thyroid function $(19,41)$, size $(42,43)$, and autoimmunity (44) in autoimmune thyroid diseases, where selenoprotein biosynthesis may be impaired (18). A number of trials in Hashimoto's thyroiditis have thus far not clarified the role of selenium supplementation (39). A single trial reported promising results for a subset of Graves' orbitopathy patients (45), and two Danish randomized trials are currently investigating clinical effects of selenium supplementation in Graves' disease (46) and chronic autoimmune thyroiditis (47).

In conclusion, in this double-blinded RCT in a population with no known thyroid diseases, selenium supplementation minutely and dose dependently affected thyroid function by decreasing serum TSH and $\mathrm{FT}_{4}$ concentrations. 


\section{Declaration of interest}

The authors declare that there is no conflict of interest that could be perceived as prejudicing the impartiality of the research reported.

\section{Funding}

Grants from the University of Southern Denmark (K H Winther), Region of Southern Denmark ( $\mathrm{K} \mathrm{H}$ Winther), the Research Council at Odense University Hospital (S J Bonnema), Novo Nordisk Foundation (L Hegedüs) and the Danish Thyroid Patient Organization ( $\mathrm{K} \mathrm{H}$ Winther) supported the writing of this paper. The Danish PRECISE pilot study has been supported by The Danish Cancer Society; The Research Foundation of the County of Funen; Cypress Systems, Inc.; The Danish Veterinary and Food Administration; The Council of Consultant Physicians, Odense University Hospital; The Clinical Experimental Research Foundation at Department of Oncology, Odense University Hospital; K.A Rohde's Foundation; Dagmar Marshall's Foundation. Pharma Nord ApS, Vejle, Denmark provided the selenium and placebo tablets. Role of funding sources: the funding sources had no role in the study design, data collection, analysis or interpretation of data, or decision to submit the manuscript for publication.

\section{Author contribution statement}

$\mathrm{S}$ Cold designed the research; $\mathrm{K} \mathrm{H}$ Winther, $\mathrm{F}$ Cold, and S Cold conducted the research; K H Winther, S J Bonnema, M Nybo, and L Hegedüs analyzed the data; B Debrabant performed the statistical analysis; $\mathrm{K} \mathrm{H}$ Winther wrote the manuscript; S J Bonnema and L Hegedüs revised the manuscript; $\mathrm{K} \mathrm{H}$ Winther had primary responsibility for final content. All authors read and approved the final manuscript.

\section{Acknowledgements}

The authors wish to thank Prof. Margaret Rayman for her intellectual input in the planning of the DK PRECISE pilot trial and for fruitful discussions of the results of this study.

\section{References}

1 Oppenheimer JH, Schwartz HL \& Surks MI. Propylthiouracil inhibits the conversion of L-thyroxine to L-triiodothyronine. An explanation of the antithyroxine effect of propylthiouracil and evidence supporting the concept that triiodothyronine is the active thyroid hormone. Journal of Clinical Investigation 197251 2493-2497. (doi:10.1172/ JCI107063)

2 Frumess RD \& Larsen PR. Correlation of serum triiodothyronine $\left(\mathrm{T}_{3}\right)$ and thyroxine $\left(\mathrm{T}_{4}\right)$ with biologic effects of thyroid hormone replacement in propylthiouracil-treated rats. Metabolism 197524 547-554. (doi:10.1016/0026-0495(75)90079-7)

3 Rijntjes E, Scholz PM, Mugesh G \& Kohrle J. Se- and s-based thiouracil and methimazole analogues exert different inhibitory mechanisms on type 1 and type 2 deiodinases. European Thyroid Journal 20132 252-258. (doi:10.1159/000355288)

4 Berry MJ, Banu L \& Larsen PR. Type I iodothyronine deiodinase is a selenocysteine-containing enzyme. Nature 1991349 438-440. (doi:10.1038/349438a0)

5 Kryukov GV, Castellano S, Novoselov SV, Lobanov AV, Zehtab O, Guigo R \& Gladyshev VN. Characterization of mammalian selenoproteomes. Science 2003300 1439-1443. (doi:10.1126/science.1083516)

6 Schomburg L \& Kohrle J. On the importance of selenium and iodine metabolism for thyroid hormone biosynthesis and human health.
Molecular Nutrition \& Food Research 200852 1235-1246. (doi:10.1002/ mnfr.200700465)

7 Arthur JR, Nicol F \& Beckett GJ. Selenium deficiency, thyroid hormone metabolism, and thyroid hormone deiodinases. American Journal of Clinical Nutrition $1993 \mathbf{5 7} 236 \mathrm{~S}-239 \mathrm{~S}$.

8 Contempre B, Duale NL, Dumont JE, Ngo B, Diplock AT \& Vanderpas J. Effect of selenium supplementation on thyroid hormone metabolism in an iodine and selenium deficient population. Clinical Endocrinology 199236 579-583. (doi:10.1111/j.1365-2265.1992.tb02268.x)

9 Combs GF Jr. Selenium in global food systems. British Journal of Nutrition 200185 517-547. (doi:10.1079/BJN2000280)

10 Rasmussen LB, Hollenbach B, Laurberg P, Carle A, Hog A, Jorgensen T, Vejbjerg P, Ovesen L \& Schomburg L. Serum selenium and selenoprotein P status in adult Danes - 8-year followup. Journal of Trace Elements in Medicine and Biology 200923 265-271. (doi:10.1016/j.jtemb.2009.03.009)

11 Rasmussen LB, Schomburg L, Kohrle J, Pedersen IB, Hollenbach B, Hog A, Ovesen L, Perrild H \& Laurberg P. Selenium status, thyroid volume, and multiple nodule formation in an area with mild iodine deficiency. European Journal of Endocrinology 2011164 585-590. (doi:10.1530/EJE-10-1026)

12 Derumeaux H, Valeix P, Castetbon K, Bensimon M, Boutron-Ruault MC, Arnaud J \& Hercberg S. Association of selenium with thyroid volume and echostructure in 35- to 60-year-old French adults. European Journal of Endocrinology 2003148 309-315. (doi:10.1530/eje.0.1480309)

13 Hurst R, Armah CN, Dainty JR, Hart DJ, Teucher B, Goldson AJ, Broadley MR, Motley AK \& Fairweather-Tait SJ. Establishing optimal selenium status: results of a randomized, double-blind, placebocontrolled trial. American Journal of Clinical Nutrition 201091 923-931. (doi:10.3945/ajcn.2009.28169)

14 Olivieri O, Girelli D, Azzini M, Stanzial AM, Russo C, Ferroni M \& Corrocher R. Low selenium status in the elderly influences thyroid hormones. Clinical Science 199589 637-642.

15 Combs GF Jr, Midthune DN, Patterson KY, Canfield WK, Hill AD, Levander OA, Taylor PR, Moler JE \& Patterson BH. Effects of selenomethionine supplementation on selenium status and thyroid hormone concentrations in healthy adults. American Journal of Clinical Nutrition 200989 1808-1814. (doi:10.3945/ajcn.2008.27356)

16 Thomson CD, McLachlan SK, Grant AM, Paterson E \& Lillico AJ. The effect of selenium on thyroid status in a polution with marginal selenium and iodine status. British Journal of Nutrition 200594 962-968. (doi:10.1079/BJN20051564)

17 Rayman MP, Thompson AJ, Bekaert B, Catterick J, Galassini R, Hall E, Warren-Perry M \& Beckett GJ. Randomized controlled trial of the effect of selenium supplementation on thyroid function in the elderly in the United Kingdom. American Journal of Clinical Nutrition 200887 370-378.

18 Schomburg L. Selenium, selenoproteins and the thyroid gland: interactions in health and disease. Nature Reviews. Endocrinology 20128 160-171. (doi:10.1038/nrendo.2011.174)

19 Hansen PS, Brix TH, Iachine I, Sorensen TI, Kyvik KO \& Hegedus L. Genetic and environmental interrelations between measurements of thyroid function in a healthy Danish twin population. American Journal of Physiology. Endocrinology and Metabolism 2007292 E765-E770. (doi:10.1152/ajpendo.00321.2006)

20 Jensen EA, Petersen PH, Blaabjerg O, Hansen PS, Brix TH \& Hegedus L. Establishment of reference distributions and decision values for thyroid antibodies against thyroid peroxidase (TPOAb), thyroglobulin (TgAb) and the thyrotropin receptor (TRAb). Clinical Chemistry and Laboratory Medicine 200644 991-998. (doi:10.1515/CCLM.2006.166)

21 Mao J, Pop VJ, Bath SC, Vader HL, Redman CW \& Rayman MP. Effect of low-dose selenium on thyroid autoimmunity and thyroid function in UK pregnant women with mild-to-moderate iodine deficiency. European Journal of Nutrition, 2014.

22 Suadicani P, Hein HO \& Gyntelberg F. Serum selenium concentration and risk of ischaemic heart disease in a prospective cohort study of 3000 males. Atherosclerosis 199296 33-42. (doi:10.1016/00219150(92)90035-F) 
23 Olivieri O, Stanzial AM, Girelli D, Trevisan MT, Guarini P, Terzi M, Caffi S, Fontana F, Casaril M, Ferrari S et al. Selenium status, fatty acids, vitamins A and E, and aging: the Nove Study. American Journal of Clinical Nutrition 199460 510-517.

24 Bates CJ, Thane CW, Prentice A \& Delves HT. Selenium status and its correlates in a British national diet and nutrition survey: people aged 65 years and over. Journal of Trace Elements in Medicine and Biology 200216 1-8. (doi:10.1016/S0946-672X(02)80002-5)

25 Combs GF Jr, Jackson MI, Watts JC, Johnson LK, Zeng H, Idso J, Schomburg L, Hoeg A, Hoefig CS, Chiang EC et al. Differential responses to selenomethionine supplementation by sex and genotype in healthy adults. British Journal of Nutrition 2012107 1514-1525. (doi:10.1017/ S0007114511004715)

26 Zeger SL \& Liang KY. Longitudinal data analysis for discrete and continuous outcomes. Biometrics 198642 121-130. (doi:10.2307/2531248)

27 Gardiner JC, Luo Z \& Roman LA. Fixed effects, random effects and GEE: what are the differences? Statistics in Medicine 200928 221-239. (doi:10.1002/sim.3478)

28 Hardin JW \& Hilbe JM. Generalized Estimating Equations. 2nd edn. Boca Raton, FL: Chapman and Hall/CRC, 2012.

29 Kohrle J, Jakob F, Contempre B \& Dumont JE. Selenium, the thyroid, and the endocrine system. Endocrine Reviews 200526 944-984. (doi:10.1210/er.2001-0034)

30 Labunskyy VM, Hatfield DL \& Gladyshev VN. Selenoproteins: molecular pathways and physiological roles. Physiological Reviews 2014 94 739-777. (doi:10.1152/physrev.00039.2013)

31 Gereben B, Zavacki AM, Ribich S, Kim BW, Huang SA, Simonides WS, Zeold A \& Bianco AC. Cellular and molecular basis of deiodinaseregulated thyroid hormone signaling. Endocrine Reviews 200829 898-938. (doi:10.1210/er.2008-0019)

32 Rayman MP. Selenium and human health. Lancet 2012379 1256-1268. (doi:10.1016/S0140-6736(11)61452-9)

33 Chanoine JP, Safran M, Farwell AP, Dubord S, Alex S, Stone S, Arthur JR, Braverman LE \& Leonard JL. Effects of selenium deficiency on thyroid hormone economy in rats. Endocrinology 1992131 1787-1792.

34 Stoedter M, Renko K, Ibáñez E, Plano D, Becker NP, Martitz J, Palop JA, Calvo A, Sanmartín C \& Schomburg L. Strong induction of iodothyronine deiodinases by chemotherapeutic selenocompounds. Metallomics 20157 347-354. (doi:10.1039/C4MT00273C)

35 Basalaeva NL. Iodine-induced thyroid blockade: role of selenium and iodine in the thyroid and pituitary glands. Biological Trace Element Research 2013154 244-254. (doi:10.1007/s12011-013-9708-6)

36 Laurberg P, Jorgensen T, Perrild H, Ovesen L, Knudsen N, Pedersen IB, Rasmussen LB, Carle A \& Vejbjerg P. The Danish investigation on iodine intake and thyroid disease, DanThyr: status and perspectives. European Journal of Endocrinology 2006155 219-228. (doi:10.1530/eje.1. 02210)

37 Thomson CD, Campbell JM, Miller J, Skeaff SA \& Livingstone V. Selenium and iodine supplementation: effect on thyroid function of older New Zealanders. American Journal of Clinical Nutrition 200990 1038-1046. (doi:10.3945/ajen.2009.28190)

38 Bulow Pedersen I, Knudsen N, Carle A, Vejbjerg P, Jorgensen T, Perrild H, Ovesen L, Banke Rasmussen L \& Laurberg P. A cautious iodization program bringing iodine intake to a low recommended level is associated with an increase in the prevalence of thyroid autoantibodies in the population. Clinical Endocrinology 201175 120-126. (doi:10.1111/j.1365-2265.2011.04008.x)

39 van Zuuren EJ, Albusta AY, Fedorowicz Z, Carter B \& Pijl H. Selenium supplementation for Hashimoto's thyroiditis: summary of a cochrane systematic review. European Thyroid Journal 20143 25-31.

40 Mannisto T, Surcel HM, Bloigu A, Ruokonen A, Hartikainen AL, Jarvelin MR, Pouta A, Vaarasmaki M \& Suvanto-Luukkonen E. The effect of freezing, thawing, and short- and long-term storage on serum thyrotropin, thyroid hormones, and thyroid autoantibodies: implications for analyzing samples stored in serum banks. Clinical Chemistry 200753 1986-1987. (doi:10.1373/clinchem. 2007.091371)

41 Hansen PS, Brix TH, Sorensen TI, Kyvik KO \& Hegedus L. Major genetic influence on the regulation of the pituitary-thyroid axis: a study of healthy Danish twins. Journal of Clinical Endocrinology and Metabolism 200489 1181-1187. (doi:10.1210/jc.2003-031641)

42 Brix TH, Kyvik KO \& Hegedus L. Major role of genes in the etiology of simple goiter in females: a population-based twin study. Journal of Clinical Endocrinology and Metabolism 199984 3071-3075.

43 Hansen PS, Brix TH, Bennedbaek FN, Bonnema SJ, Kyvik KO \& Hegedus L. Genetic and environmental causes of individual differences in thyroid size: a study of healthy Danish twins. Journal of Clinical Endocrinology and Metabolism 200489 2071-2077. (doi:10.1210/jc. 2003-031999)

44 Brix TH, Hansen PS, Kyvik KO \& Hegedus L. Aggregation of thyroid autoantibodies in first-degree relatives of patients with autoimmune thyroid disease is mainly due to genes: a twin study. Clinical Endocrinology 200460 329-334. (doi:10.1111/j.1365-2265. 2004.01983.x)

45 Marcocci C, Kahaly GJ, Krassas GE, Bartalena L, Prummel M, Stahl M, Altea MA, Nardi M, Pitz S, Boboridis K et al. Selenium and the course of mild Graves' orbitopathy. New England Journal of Medicine 2011364 1920-1931. (doi:10.1056/NEJMoa1012985)

46 Watt T, Cramon P, Bjorner JB, Bonnema SJ, Feldt-Rasmussen U, Gluud C, Gram J, Hansen JL, Hegedus L, Knudsen N et al. Selenium supplementation for patients with Graves' hyperthyroidism (the GRASS trial): study protocol for a randomized controlled trial. Trials 201314 119. (doi:10.1186/1745-6215-14-119)

47 Winther KH, Watt T, Bjorner JB, Cramon P, Feldt-Rasmussen U, Gluud C, Gram J, Groenvold M, Hegedus L, Knudsen N et al. The chronic autoimmune thyroiditis quality of life selenium trial (CATALYST): study protocol for a randomized controlled trial. Trials 201415 115. (doi:10.1186/1745-6215-15-115) 